\title{
Consumer Health Information Resources on Pregnancy, Birth, and Fertility
}

\author{
Compiled by Julie Alati-it and Alison Pinches
}

If you are planning for conception, pregnancy, or birth, these events bring up a myriad of questions for all involved. With the preparation that follows, fertility issues and familial expectations are often at the forefront. As each woman is different and may have a wide spectrum of expectations and previous experiences, there is much to consider and a hefty amount of information to sift through. Advice, often unsolicited or from well-meaning family and friends, can be outdated or not evidence-based. As always, the Internet offers a wide range of opinions and suggestions from Twitter to blogs to pseudo-medical web pages, which can be confusing and contradictory. The resource list we've put together is not exhaustive, but provides some sense of where to look for highly accessible, evidence-based information both in print and online for library patrons.

\section{Websites}

Service Canada. Having a Baby

http://www.servicecanada.gc.ca/eng/lifeevents/baby.shtml

This resource provides explanations about parental leave, registration and benefits. Prenatal programs are listed by province or territory. This site also links to programs and services for new parents offered by other federal departments and agencies. Other items of interest are the "Sensible Pregnancy Guide", a customized 10-month calendar; a healthy pregnancy quiz; and beforeand after-pregnancy guides.

\section{Healthy Canadians. Pregnancy and Fertility}

http://www.healthycanadians.gc.ca/health-sante/pregnancygrossesse/index-eng.php

Useful web pages on multiple births; egg, sperm, embryo donation, and surrogates; fertility (including cancer and fertility as well as fertility treatments); and genetic counselling and screening are all organized by topic. Each includes definitions and glossaries.

The Society of Obstetricians and Gynaecologists of Canada. Women's Health Information http://sogc.org/womens-health-information/

A resource maintained by the Society of Obstetricians and Gynaecologists of Canada, it includes information on birth plans, births (breech and caesarean), age and fertility (trends and treatments), herbal remedies, umbilical cord blood, normal childbirth, and vaginal birth after caesarean. All of these sections provide definitions and further resources.

Dietitians of Canada. Your Health - Pregnancy http://www.dietitians.ca/your-health/nutrition-a-z/pregnancy

Maintained by the Dietitians of Canada, this website supplies a list of foods that contain folate and other foods that are important in the preconception stage. There is also a link to a "Pregnancy Food Guide Tracker", in which the Canadian Food Guide is summarized for pregnancy.

Health Information Translations

https://www.healthinfotranslations.org/topic/pregnancy_ and_baby_care/46013/

This is a very useful website, maintained by health education specialists from four health systems in Ohio. Health information can be retrieved by health topic, language, and keyword. The information is provided in a variety of media: print, audio, and short video. Although the information is from an American perspective, there are some very useful topics such as signs and stages of labour, recovery after a Caesarean section, types of tests, and breastfeeding, all of which are thoroughly explained in plain language. Available languages of translated material include French, Chinese (Traditional or Simplified), Tagalog, Somali, and Vietnamese.

\section{Cancer During Pregnancy}

http://www.cancer.ca/en/cancer-information/diagnosis-andtreatment/cancer-during-pregnancy/?region $=\mathrm{ab}$

A very informative website maintained by the Canadian Cancer Society that provides useful information on the incidence of cancer during pregnancy, diagnosis of cancer during pregnancy, cancer treatment during pregnancy, effects on the fetus, and breastfeeding.

\section{MotherRisk}

http://www.motherisk.org/women/index.jsp

An online resource maintained by the Hospital for Sick Children (affiliated with the University of Toronto), MotherRisk provides evidence-based information on a wide variety of pregnancy topics including drugs, 
conditions and diseases, herbal products, HIV and treatment, and breastfeeding. Information is organized by topic, and the user can view detailed information. This site also provides a wide variety of links to national centres, associations, and general pregnancy and parenting information.

\section{Pregnancy and Babies Resource Centre}

http://www.aboutkidshealth.ca/En/ResourceCentres/PregnancyBabies/Pages/default.aspx

Information is organized in chronological order from preconception and baby development to the first year of life. The content was written by a team of health professionals affiliated with the Hospital for Sick Children in Toronto. Pregnancy and parenting sections include information for the expecting father and overdue pregnancy. Although the content of this site is for the most part in plain language, some sections are not as easily accessible as others.

\section{Books}

Boston Women's Health Collective. Our Bodies, Ourselves: Pregnancy and Birth. New York: Simon and Shuster; 2008. (http://www.ourbodiesourselves.org/book/chapter.asp?id= 21)

A classic resource produced by the Boston Women's Health Book Collective, this book provides an overview of the entire journey from pregnancy planning to giving birth. Although written from an American perspective, it includes areas not covered by many other books such as models of maternity care, preparations for childbirth (birth plan options), coping with pain, and life as a new mother (depression and networks of support). Additionally, there are sections on miscarriage and pregnancy after infertility or pregnancy loss. The corresponding website contains book excerpts, links to blogs, a list of recommended of books, and films about childbirth.

Harms R, Johnson R, Murray M. editors. Mayo Clinic Guide to a Healthy Pregnancy. Intercourse: Good Books; 2011.

Written by a multidisciplinary team that includes an obstetrician, a certified nurse-midwife, and a paediatrician from the Mayo Clinic, this book provides information on pregnancy, childbirth, and newborns in chronological order. There are separate sections with tables of contents at the beginning of each section, making it very easy to look up information. The information is laid out in a nonjudgemental way with colour photos and diagrams. "Decision guides" are provided, with useful sections that assist in making informed decisions on how to select a healthcare provider, as well as prenatal testing options. An easy-to-use reference guide on pregnancy topics and health concerns, this book covers everything from morning sickness to preterm labour. Written in a nonalarmist tone, it contains straightforward information and will tell you what to look forward to and what to start to think about.

The accompanying website to this book is also a handy reference tool. There are various links for in-depth information on yoga, sleep, vaccines, and travel. http:// www.mayoclinic.com/health/pregnancy-week-by-week/MY 00331

Singer A. Creating Your Perfect Family Size: How to Make an Informed Decision About Having a Baby. San Francisco: Jossey-Bass; 2011.

Written by a researcher/family therapist, this book explores why people might want to have children, the best time to have children, ideals on family size, and how old or new family traditions affect your family size. The unique attributes of this resource are the self-reflective exercises and self-test questions that encourage reality checks at the end of each chapter. This book offers suggestions on how to make an informed decision about family size and how to encourage meaningful conversation and insight.

Murphy M, McDonagh-Hull P. Choosing Cesarean - A Natural Birth Plan. Amherst: Prometheus Books; 2012.

Considered a controversial book for its advocacy of a woman's right to choose caesarean section for nonmedical reasons, this work discusses the choice of caesarean section as part of birth plan options. Dr. Murphy is a practising urogynecologist and clinical assistant professor in obstetrics and gynecology at the University of Calgary, and Pauline McDonagh Hull is an investigative journalist. They make an argument that a caesarean section is as safe as a vaginal birth. While many birth plans emphasize vaginal birth, this book provides evidence-based information on caesarean section.

Ogle A, and Mazzullo L. Before Your Pregnancy: a 90-day Guide for Couples on How to Prepare for a Healthy Conception. New York: Ballentine Books; 2011.

This is one of the few guides to the preconception period that approaches the topic from the perspective of normal fertility rather than low fertility or infertility. Topics covered are: the pre-pregnancy period, emotional preparations for both men and women, nutrition, exercise, and lifestyle. The sections are easy to read and navigate. The book is fairly substantive; there is a chapter dedicated to dads-to-be and another about a baby's impact on finances complete with budget worksheets. Overall it is a very useful reference book.

Shaw G. Having Children After Cancer: How to Make Informed Choices Before and After Treatment and Build the Family of Your Dreams. Berkeley: Celestial Arts; 2011.

Written by a cancer survivor and mother of three children, this book is an excellent resource on fertility after cancer. A useful resource for both men and women, it explains topics such as how different cancers can affect fertility; how treatments such as chemotherapy, radiation, and surgery can potentially impair your fertility; clear explanations on selecting the fertility preservation method that is appropriate for freezing eggs, sperm, and embryos; and preserving ovarian tissue. This resource addresses emotional challenges and financial obstacles cancer survivors may face in their journey towards 
parenting. Other survivors' stories are used to demonstrate the difficulties and how other families successfully dealt with them.

Oktay K, Nohr Beck L, Dillion Reineck J. 100 Questions \& Answers About Cancer and Fertility. Sudbury: Jones and Bartlett Publishers; 2008.

Written by an obstetrics and gynaecology-reproductive medicine specialist, cancer-fertility patient advocate, and cancer survivor, this book this is an invaluable resource for anyone struggling with the medical, physical, and emotional turmoil of cancer and infertility. Included are patient stories in a concise and accessible format. As in the rest of the 100 Questions \& Answers series, the information is written in a question-answer format.

Platt E, Pinette MG, Campbell B, Tetreau A. 100 Questions \& Answers About Your High-risk Pregnancy. Sudbury: Jones and Bartlett Publishers; 2009.

The term "high-risk pregnancy" often invokes anxiety in women. This resource is written by medical staff and contains easily accessible information for patients who have experienced high-risk pregnancies. The information is divided into detailed sections and includes basic definitions, prenatal testing, mother's health, baby's health, concerns in high-risk pregnancy, and facing loss in high-risk pregnancy. Patients' experiences are included throughout the book. The section on facing loss is written in language that is kind, straightforward, and acknowledges that loss is a painful event.

Douglas A. The Mother of All Pregnancy Books: an AllCanadian Guide to Conception, Birth \& Everything in Between. Toronto: J. Wiley \& Sons Canada; 2011.

A comprehensive reference guide for Canadian parents, this book includes information from preconception to post-baby arrival. It also includes information on dealing with loss and grief. Content is accessible and easy to find, and the tone is straightforward and doesn't gloss over possibilities of anything bad happening. In the various scenarios described, the author uses experiences from mothers and pregnant women to enhance explanations of the various options available to pregnant women, without pushing a particular opinion.

Sacks D. Diabetes \& Pregnancy: a Guide to a Healthy Pregnancy for Women Who Have Type 1, Type 2, or Gestational Diabetes. Alexandria: American Diabetes Association; 2011.

A useful resource for any woman who has diabetes and who is thinking of starting a family, it contains information about why having diabetes requires special preparation, how to get yourself and your blood glucose levels into the best shape possible before getting pregnant, and what to expect from medical treatment while preparing for and during your pregnancy. The language used in this book is accessible, and the content is organized in manageable sections, with helpful charts and diagrams. There is a medication list of insulins commonly used, blood glucose control, and diabetes complications during pregnancy. Overall, it is a helpful resource for women who are looking for reliable information on how to stay well and have a healthy baby.

Sears W, Sears M. The Birth Book: Everything You Need to Know to Have a Safe and Satisfying Birth. Boston, MA: Little, Brown \& Co; 1994

Considered a pregnancy bible, this book was written by a paediatrician and a nurse, who are also parents of 8 children and have decades of both personal and professional experience. Some of the topics included in this book are selecting your birth team, defining the father's role, selecting a birth class, choosing or avoiding anaesthesia, and turning a surgical birth into a positive experience.

Curtis G, Schuler J. Your Pregnancy After 35 (Revised Edition). New York: Da Capo Press; 2009.

One of the only books on pregnancy over 35 , this book was written by an obstetrician and a pregnancy educator. Topics include tests for baby and mother, nutrition and weight management, and achieving pregnancy after 35 . There are also sections on challenges as a single mother, preparing to return to work, and how to investigate childcare options. Other helpful and useful information includes how to deal with co-workers, first-time versus repeat pregnancy, unsolicited opinions, advice on being an "older mother", and older couples becoming parents.

Julie Alati-it, BA (Hons)

Information Specialist, Knowledge Resource Services (University of Calgary/Alberta Health Services)

Women's Health Centre, Foothills Medical Centre

144129 th St NW, Calgary, AB T2N 4J8

Alison Pinches, BA

Knowledge Resource Specialist, Knowledge Resource Service, Alberta Health Services

Patient and Community Resource Centre, South Health Campus

4448 Front St SE, Calgary, AB T3M 1 M4 